\title{
Student incentives: More than a free condom
}

\section{Ben Wraith \\ Students' Union University of Greenwich}

The University of Greenwich used to charge a $£ 50$ fine if a student failed to register before a certain deadline. Would this $£ 50$ 'fine' for late registration be more effective if it was changed to a $£ 50$ 'bonus' for early registration? Besides a possible increase in efficiency, could this small change bring about increased happiness both for staff, who become bonus-givers rather than fine-imposers, and students, who are confronted with pleasing bonuses rather than fines and harsh language? Simply, by reframing the proposition, we may get a very different response, as argued by Thaler and Sunstein (2008).

There are questions to be asked in other areas of the university too. Could publishing all essays raise standards? If every student was aware that their peers could browse their work, would they put extra effort in? Would this also raise standards each subsequent year, as each cohort studies the work of their predecessors and seeks to improve on it? We already seem to do this by releasing copies of previous good examples of essays and dissertations, in order to give an indication of what current students should be aiming for. In addition, perhaps it would also put an end to any accusations of favouritism aimed at lecturers.

With social norms being proven to be stronger than market norms (Ariely and Heyman, 2004), the above idea becomes more attractive. We should also consider whether some otherwise sound ideas have unintentional negative outcomes. Does the anonymous nature of electronic coursework submission hide a multitude of sins? Many companies have found that by asking employees to put their name to their work, they can swiftly raise standards. However, short of reverting to students handing work in physically to their tutors, what can we do, when electronic submission brings about so many other advantages, including protecting anonymity for marking? To simulate the act of 'signing off' the work, could we present students with a page (one step prior to upload) featuring their photo and a statement along the lines, 'I, Ben Wraith, am proud of this work, which is all my own, furthermore, I am delighted for this work to be circulated far and wide'?

Personalising a problem often helps people to empathise, a tactic used successfully in direct mail campaigns by many major charities. So, say there is an issue with students not returning library books promptly after a request by another student, would sending the borrower a photo (with permission of the requester) and a few words, a plea perhaps, boost the speed of return?

A similarly creative approach could also have been applied to tuition fees. Greenwich used to charge an amount lower than the maximum allowed. This offered possibilities; could we have rolled the cost of freshers' week, a laptop, graduation and other things into a top-up pack? Mobile phone companies have been offering 'bolt-ons' and 'extras' for many years. Students could have added this top-up pack to their annual fee and, although they would have ended up paying the maximum fee, they would have cut down on their upfront costs whilst studying. Rolling up the cost into the fee loan would have meant lower interest rates and repayments based on the ability to pay for most students.

Surely better than putting it all on a credit card? The university could have considered it a higher education version of a loss leader. By ensuring that many costs were rolled up early in the 
academic year, the effect could have been that fewer students experienced financial difficulties later in the year. By reducing this often negative impact on academic performance, the cost of setting up the scheme could have been attractive? i.e. fewer students dropping out and/or improved results.

Also of interest in the above scenario is how relativity (in a marketing sense) would impact on prospective students. The mere presence of a higher priced option (tuition fee plus top-up) could make the lower price option (tuition fee, no top-up or cheaper top-up) more attractive. In the same way, restaurants often use a higher price starter to encourage patrons to purchase the second highest priced dish - and often the dish with the highest profit margin (Ariely, 2008).

The important thing to recognise is that we can alter some of the more traditional methods of higher education to improve them. By borrowing the underlying principles of clever ideas from restaurants, smoothie makers, charities etc. we can improve on sector-based benchmarking, by comparing our problems and solutions to more than just fellow higher education institutions. Some may find any moves to ape the commercial world worrying in a climate of commercialising education, but it is the techniques that we should borrow and not the underlying aim. If our purpose is to expand opportunities for students to access and gain a high-quality education, then we should have nothing to fear when borrowing the tools we need to achieve it.

\section{References}

Ariely, D. (2008) Predictably Irrational: The Hidden Forces that Shape our Decisions. London: Harper Collins.

Ariely, D. and Heyman, J. (2004) 'Effort for Payment: A Tale of Two Markets'. Psychological Science 15(11): 787-93.

Thaler, R. and Sunstein, C. (2008) Nudge. London: Penguin Books. 